\title{
Nitrogen-doped Graphene Sheets Prepared from Different Graphene-Based Precursors as High Capacity Anode Materials for Lithium-Ion Batteries
}

\author{
Ming-Hua Jiang, Dandan Cai ${ }^{*}$, Ni Tan \\ School of Chemistry and Pharmaceutical Sciences, Guangxi Normal University, Key Laboratory for \\ the Chemistry and Molecular Engineering of Medicinal Resources (Ministry of Education), Guilin, \\ 541004, P. R. China. \\ *E-mail: caidandan86@163.com
}

doi: $10.20964 / 2017.08 .14$

Received: 1 May 2017 / Accepted: 2 June 2017 / Published: 12 July 2017

\begin{abstract}
The nitrogen $(\mathrm{N})$ doping in graphene-based materials has been considered as an effective approach to improve the lithium storage performance of lithium-ion batteries. Thus, the studies of the influence of $\mathrm{N}$-doped graphene from different precursors on lithium storage properties are urgently needed. Herein, three different N-doped graphene sheets (N-GT, N-GN, N-RGN) anode materials of LIBs was prepared using the graphite oxides, graphene oxides and reduced graphene oxides as precursors respectively and thermal annealing with melamine. Microstructure tests show the N-RGN possess higher specific surface area $\left(687.7 \mathrm{~m}^{2} \mathrm{~g}^{-1}\right)$, larger interlayer distance and more active sites due to the expanded graphene layers of reduced grapheme oxides than N-GT or N-GN. Electrochemical experiments results show that the order of lithium storage properties is N-RGN $>\mathrm{N}-\mathrm{GN}>\mathrm{N}-\mathrm{GT}$ based on specific capacity and cycle performance, which can be explained for specific surface area of material as one of the key structural parameters. Moreover, a high initial reversible capacity of 1250.8 $\mathrm{mAh} \mathrm{g}^{-1}$ can be achieved for N-RGN at a current density of $100 \mathrm{~mA} \mathrm{~g}^{-1}$.
\end{abstract}

Keywords: N-doped graphene; Thermal annealing; Different precursors; Anode materials; Lithiumion batteries.

\section{FULL TEXT}

(C) 2017 The Authors. Published by ESG (www.electrochemsci.org). This article is an open access article distributed under the terms and conditions of the Creative Commons Attribution license (http://creativecommons.org/licenses/by/4.0/). 